\title{
COMMUNICATIONS
}

\section{OCULAR HISTOLOGY IN PREMATURE INFANTS WITH REFERENCE TO RETROLENTAL FIBROPLASIA}

\author{
BY \\ B. A. WARD \\ Department of Pathology, Institute of Ophthalmology, University of London
}

IN the years following the first description of retrolental fibroplasia by Terry (1942), the reported incidence of the disease rose alarmingly and it was soon considered by many to be the most common cause of blindness in children under school age. Much thought and study have been given to the aetiology of retrolental fibroplasia and almost every aspect of pregnancy and premature baby management has come under close scrutiny. About the time this investigation was planned, interest was focused on the question of pre-natal versus post-natal origin; was some predisposing condition or nucleus of disease present at birth? Whilst there was little clinical evidence of congenital affection, some investigators (Heath, 1950; Reese and Blodi, 1951; Reese, and others, 1952) described pathological changes in eyes obtained from premature infants at or within the first day or two of birth.

It was, therefore, decided to examine the eyes from a significant number of premature infants in search of early signs of retrolental fibroplasia and of physiological or pathological conditions which might predispose to this disease.

\section{Review of the Literature}

Previous reports on such material, reviewed in chronological order, have been carried out by Heath (1950) who stated that forty eyes of foetuses of 4 to 9 months' gestation, studied microscopically, showed differentiation consistent with gestational ages. None showed retrolental fibroplasia or significant retinal changes. The retina, according to its degree of prematurity, showed loose coaptation and the usual variable anterior insertion. An occasional well-contained haemorrhage was seen in the retina. No excess of vascular tissue and no disruption, heavy staining, or marked oedema of retinal structure were seen, and no vitreous haemorrhage was noted.

Reese and Blodi (1951) examined the eyes of 93 premature infants who were either stillborn or died shortly after birth. Fourteen sets were too macerated for useful observation; of the remaining 79 sets, 21 were from stillbirths. They found neo-vascularization of the retina spreading into the vitreous in both eyes of one case in which the birth weight was 1,950 g., and in another case they found new vessels on the surface of the retina. These cases would now be diagnosed as an early stage of retrolental fibroplasia. An inflammatory process of the uvea was found in 18 per cent., usually only in the choroid. Occasionally cells were seen in 
the vitreous, and, in one case particularly, around the hyaloid system. The degree of infiltration was not specified, but that shown in their illustration was of considerable extent. A large retinal haemorrhage in the region of the ora was noted in 14 per cent. of cases, and small haemorrhages elsewhere were extremely common. Massive congestion of the retina and uvea occurred in 14 per cent. of cases. The authors commented that such conditions can be due to post-mortem change in association with maceration, although marked dilatation was also seen in eyes showing no other post-mortem change.

Dixon and Paul (1951), who examined twenty premature and ten full-term infants, concluded that factors which interfere with development may prevent normal adherence between the layers of the optic cup. Heath (1951) in a second paper on the examination of eyes from an unspecified number of stillborn premature infants ranging from 3 months to full term (it is not clear how many of these were included in his first report), concluded that some oedema and occasional retinal haemorrhages occurred, but found no significant herniating neo-vascular tissue. He pointed out that in the oral zone, capillary structure was relatively sparse and the endothelial cells small and less deeply staining, that the internal limiting membrane stopped near the point at which the retinal loop began, and that Müller's fibres were absent. The retinae of premature infants in general were also inserted well anteriorly, sometimes on the pars plana and ciliary body.

Friedenwald and others (1951) examined premature stillborn infants' eyes and found sprouting capillaries and accompanying "glial" proliferations in the retinae, but these had an orderly arrangement and the capillary whorls likened to glomerular tufts were essentially lacking in the normal developing process. Reese and others (1952) describe the examination of 97 premature infants whose birthweights ranged from 300 to $2,500 \mathrm{~g}$. (It is not clear how many of these are included in the material for their first paper). They found two cases of early retrolental fibroplasia: one stillbirth of $1,950 \mathrm{~g}$. with a mass of neovascular tissue in the vitreousdescribed in their earlier series-, and an infant of unknown birth weight who died within the first 48 hours of life, showing increased "glial" and endothelial cell and capillary formation in the equatorial region, and an apparent break-through into the vitreous in an area of folded retina in one eye. Examining further the relationship of retinal and choroidal hyperaemia to post-mortem change, they found that the two ran parallel, and, as hyperaemia was not more common in infants of low birth weight, concluded it could not be an early stage of retrolental fibroplasia. Absence or detachment of the internal limiting membrane in the region of the ora-a common finding-was similarly considered to be related to maceration and not to birth weight.

Excluding foetuses (i.e., infants with a birth weight of under 300 g.), retinal haemorrhages were found in 25 per cent. of cases and situated in the oral region in 10 per cent. Cells in the uveal tract, previously regarded as inflammatory, are identified by these authors as foci of extra-medullary haemopoiesis and marked for further investigation. Incidental congenital anomalies, not common in this series, included retrobulbar cyst with microphthalmos, retinal dysplasia, retinal rosettes, iris cysts, retinal tissue in the pars plana, and accumulations of large polygonal cells with eosinophilic granules on the ciliary epithelium.

To summarize the literature on this subject, no evidence was found of vascular proliferation in " normal " prematures except for the case described 
by Reese and others (1952) of an infant of unknown birth weight who died aged 48 hours and showed signs of early retrolental fibroplasia, and the statement by Heath (1951), describing the primary retinal disease which occurs in the anterior differentiated retina at its insertion, that these " dissociating elements (vascular dilatation, oedema, haemorrhage, and endothelial proliferation) could be found within a day of birth", though they might not develop until weeks later.

It is generally agreed that loose retinal coaptation, anterior retinal redundancy, and variable anterior insertion are premature ocular characteristics. Dixon and Paul (1951) stressed the development of adherence between the layers of the optic cup and suggested that some factor affecting this process was of importance in retrolental fibroplasia. Wolff (1950) had suggested that this factor might be some noxious stimulus which reached the embryo in the first few months of intra-uterine life causing the retina to remain unattached, so that true detachment ensued, followed by mild uveitis and retrolental fibroplasia, which was thus due to the formation of a cyclitic membrane.

Inflammatory processes of the uvea are described as occurring in 18 per cent. of cases (Reese and Blodi, 1951), and the theory has been put forward that this represents extramedullary haemopoiesis.

Defects of the internal limiting membrane and Müller's fibres in the oral zone were described by Heath (1950) and Reese and Blodi (1951), but on further investigation Reese and others (1952) showed these changes to be related to maceration and not to birth weight. Retinal and choroidal hyperaemia were similarly shown to run parallel to post-mortem change.

Heath (1950) considered some degree of retinal oedema and occasional haemorrhage to be commonplace. Reese and others (1952) found retinal haemorrhages occurring in 25 per cent. of cases with birth weight of over $300 \mathrm{~g}$., and stated that in 10 per cent. the haemorrhage was considerable and situated in the region of the ora.

\section{Purpose of Present Study}

In this study, attention will be chiefly directed towards retinal vascularization and coaptation. By comparing the characteristics of cases showing variations of these processes with the average characteristics of the eyes from one hundred premature babies, an attempt will be made to assess the significance of these variations with particular reference to retrolental fibroplasia.

\section{Material}

The material was obtained in the British Isles; 109 pairs of eyes were received in response to a Medical Research Council appeal. From these were excluded two cases of definite early retrolental fibroplasia, two cases of anencephaly, one case of intra-uterine keratouveitis, and four cases in which, owing to advanced post-mortem degeneration or maceration, efficient examination was not considered possible. 
The material reported on was made up as follows:

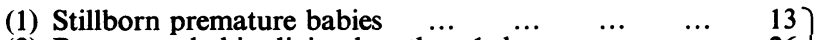

(2) Premature babies living less than 1 day $\quad \ldots . \quad \ldots \quad 26$

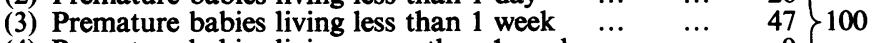

(4) Premature babies living more than 1 week ... ...

(5) Premature babies of unknown age or weight ...

$\cdots$

5

The degree of post-mortem degeneration encountered varied enormously depending on the time between death and fixation. In a few cases formalin had been injected intraocularly immediately after death.

\section{Method}

On reception the eyes were opened by horizontal section and any macroscopic changes noted; they were then dehydrated and embedded in celloidin, and two to three sections were cut (through the optic disc unless otherwise indicated) and stained with haematoxylin and eosin and with periodic acid-Schiff stain.

Later a number of unfixed eyes were injected with Indian ink via the central retinal vessels, frozen to facilitate removal of the vitreous, and fixed in 10 per cent. formol saline. They were then opened coronally in the oral region; the lens and vitreous were removed,

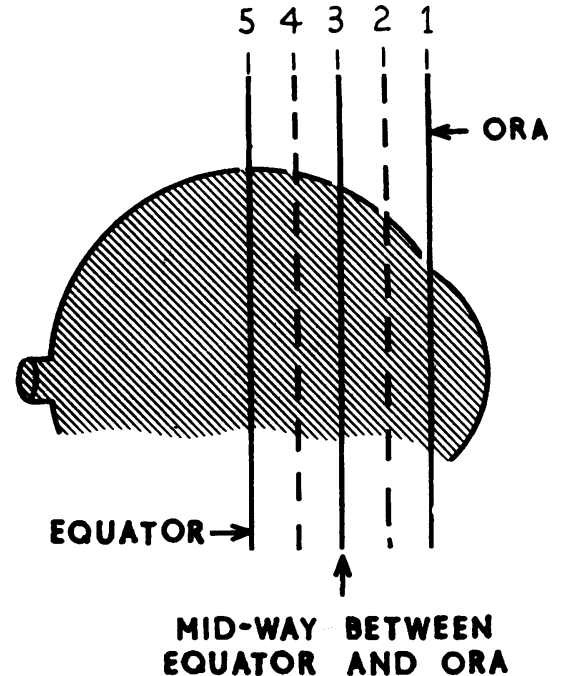

Fig. 1.-Method of corneal sectioning. and the retinae examined in situ, before removal, staining, and mounting as a flat preparation.

A comparable series of stillbirths and live births of ages ranging from 2 to 12 days were sectioned coronally and sections stained with haematoxylin and eosin in the areas numbered 1-2-3-4-5 in Fig. 1. These positions were estimated arbitrarily by the microtomist.

\section{Results and Conclusions}

Retinal Vascularization.--The normal degree of vascularity and quantity of vaso-formative tissue in the immature retina appeared to vary widely and it became apparent that folding, section thickness, and post-mortem change affected microscopic appearances profoundly. However, in thirteen cases it was decided that deviation from the normal, based on examination of 100 eyes, was noteworthy. The abnormal changes observed comprised:

(a) diffuse thickening of the nerve fibre layer due to an increase in endothelial and " glial " cells, since shown to be mesenchymal in origin (Ashton, 1954; Serpell, 1954).

(b) glomerular whorls, columns, and solid masses, composed chiefly of small spindle-shaped hyperchromatic mesenchymal cells and to a lesser degree of larger, more differentiated, palely-staining endothelial cells, with the small number of undifferentiated cells, histiocytes, and other primitive mononuclears commonly seen in association with neovascular tissue.

In cases in which the process appeared to have broken through into the 
vitreous, retinal folds, maceration, and other vitiating factors were usually present, and it was felt the appearance was almost certainly that of an artefact. For purposes of comparing the characteristics of cases showing unusual quantities of vaso-formative tissue with the average characteristics of the total series of 100 cases, the abnormal cases were divided into three groups. Vaso-formative tissue was commonly more abundant at the anterior limit of retinal vascularization in the region where maximal vascular growth occurs, a high proportion of cases showing a growing tip. In this area, clumps of mesenchymal and endothelial cells of moderate dimensions were classified as within normal limits (Fig. $2 a$ ).

GrouP A.-These were defined as showing clumps of vascular and vaso-formative tissue of moderately increased dimensions at the growing tip. Three cases fell into this category (Fig. $2 b$ ).

GROUP B.-These were of intermediate significance; they showed larger single masses anteriorly or minor masses recurring posteriorly. Three cases fell into this group (Fig. $2 \mathrm{c}$ ).

GrouP C.-These showed larger masses both at the anterior limit of vascularization and recurrently behind this area (Fig. $2 d$ ).

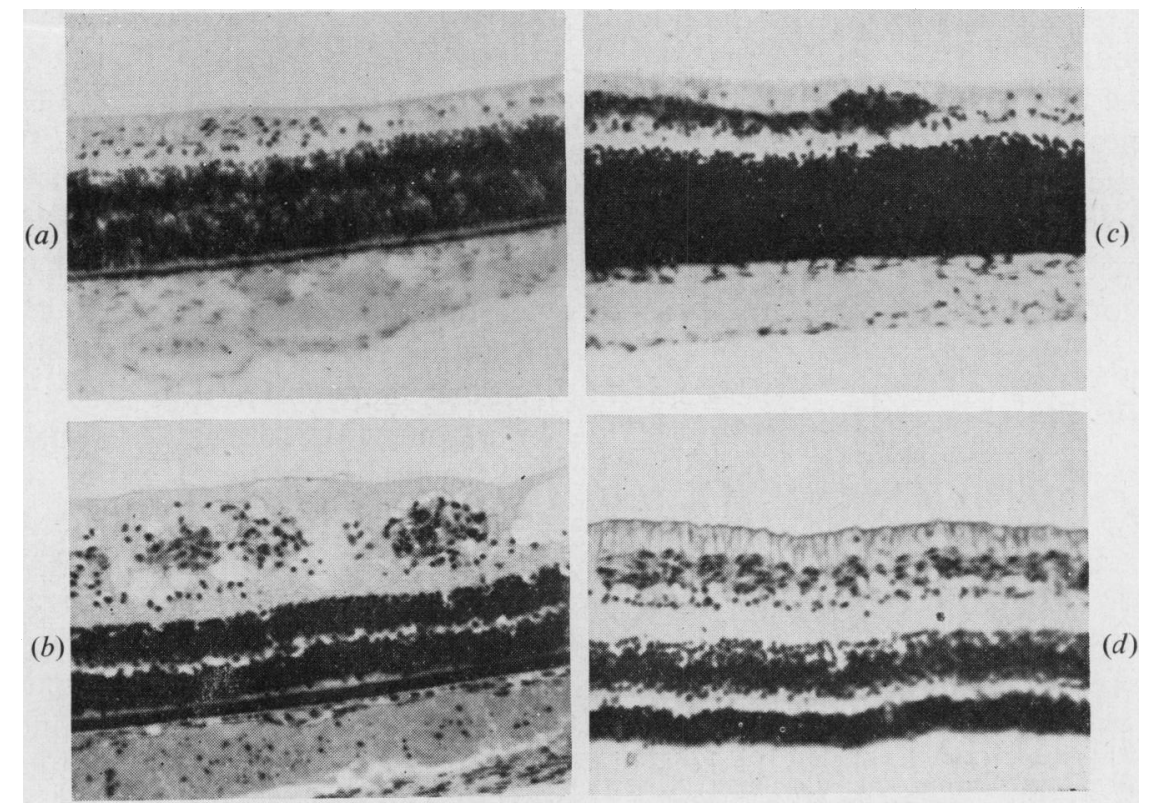

FIG. 2. (a).-Usual quantity of vaso-formative tissue at growing tip of retinal vessels.

(b).- Group "A" type of vaso-formative tissue proliferation. $\times 120$.

(c).-Group " $B$ " type of vaso-formative tissue proliferation. $\times 120$.

(d).-Group " $\mathrm{C}$ " type of vaso-formative tissue proliferation. $\quad \times 120$.

Retinal vascular development is usually described as commencing at the $100 \mathrm{~mm}$. (approx. 4 months) stage in the foetus, as endothelial budding 
arising from the hyaloid vessels (Versari, 1910; Bach and Seefelder, 1914; Mann, 1928). This process of advancing syncytial columns of mesenchymal cells followed by canalization spreads peripherally in the nerve fibre layer and also towards the inner nuclear layer, and is said to be complete by the eighth month of intra-uterine life.

Michaelson (1948), in a detailed study of six human foetuses injected with Indian ink, showed that vascularization spreads from the optic disc as four complexes destined to become the definitive nasal and temporal vessels; the vascular complexes, roughly diamond-shaped, are at first separated by avascular retina; at an early stage, the advancing columns of mesenchymal cells present a continuous front with probably a forward peak at the centre of each complex until vascularization is complete. Michaelson also showed that growth took place chiefly from the veins, and he stressed the difference between the small mesh of the developing capillary net with its large-bore, jointed, angular vessels, and the small-bore of the adult net with larger, rounded vessels. He showed that the peri-arterial capillary free zone is more marked in the developing vascular system, and he found no difference in growth-rate between the nasal and temporal vessels, showing that their simultaneous arrival at the periphery was due to the temporal vessels budding out first and attaining some millimetres of growth before the nasal complexes started.

The first step to assess vascular development in this study was the examination of horizontal sections and the estimation of the distance in millimetres of vascular or vaso-formative tissue from the ora: one slide from each eye was examined and the most advanced point noted. Theoretically, inaccuracy might be due first to the size of the capillary net; secondly to the fact that a horizontal section might not pass through the most advanced peak of a

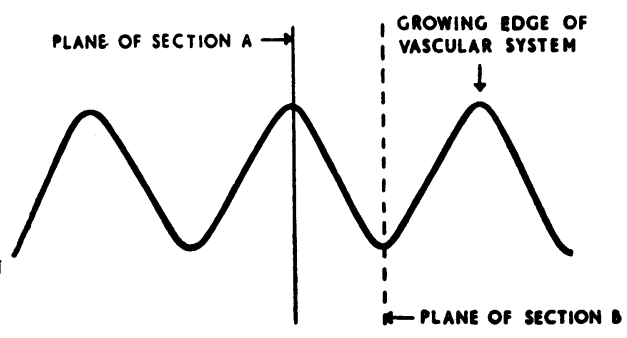

Fig. 3.-Inaccurate estimation of progress of retinal vascularization due to plane of section (arrow) coinciding with plane of growth. vascular system advancing in a similar plane(Fig. 3); thirdly to the possibility of cutting through an avascular periarterial zone, and missing the growing capillary net in front of it (because of displacement of tissue by maceration and technical procedures).

Duration of pregnancy is generally considered to be the most accurate guide to the prematurity of an infant, but in view of the relationship between birth weight and retrolental fibroplasia, the results were first related to weight, and it was found that in the under-2 lb. group of infants (24-32 weeks' pregnancy) retinal vascularization had never reached the ora. In babies of heavier weights there might be peripheral areas of avascularity; these were present to a very minor degree up to $5 \mathrm{lb}$. (the heaviest infant in this series). 
In view of the variation of the rate of retinal vascularization shown in the results of examination of the whole group of 100 premature infants (in the under $2 \mathrm{lb}$. group, almost $5 \mathrm{~mm}$. distance), a series comprising foetuses obtained at hysterotomy and stillborn infants was first examined to eliminate the error due to the effects of extra-uterine growth. This showed that:

(i) the retina was avascular at from 8 to 12 weeks;

(ii) early vascularization was present at the posterior pole at 12 to 13 weeks;

(iii) vessels and vaso-formative tissue, which had reached the equator by 19 to 28 weeks, were $5 / 8$ of the way to the ora by 25 to 35 weeks, and $6 / 8$ of the way by 29 to 32 weeks, and had reached the ora by 29 weeks.

Next, in order to minimize the error due to the plane of the section not passing through the most advanced point of the growing tip and to give some idea of the width of this actively proliferating area at the ages and weights examined, coronal sections were cut (Fig. 1). The results showed a variation in the age at which the vessels reached the ora of from 29 to 35 weeks (though all cases were in the 2 to $3 \mathrm{lb}$. group). In the youngest case examined (a 28 weeks' pregnancy, 1 to $2 \mathrm{lb}$. group), the retinal vessels had grown $5 / 8$ of the distance to the ora. Active vaso-formative tissue was present anteriorly in seven cases and was distributed over an area of approximately one-quarter of the total distance from the optic disc to the ora $(9 \mathrm{~mm}$.). In all these cases, periodic acid-Schiff (PAS) positive granules were present in the proliferating area.

To assess and compare the effects of post-natal vascular growth, a comparable series of nine live births ranging in age from 2 to 12 days were similarly examined by vertical section; they showed the same variation in growth rate, though the ora appeared to be vascularized slightly later, at fróm 32 to 36 weeks. Active vaso-formative tissue was present to a minor degree in only four cases, and the area in which it occurred was usually less than in the stillbirth series. PAS positive granules were present in only three cases, being absent in two cases showing active vaso-formative tissueone of 2 days old and one of 7 days old.

Other interesting points noted were that the unusual proliferative changes found in Case 39 were shown to be extensive in another dimension, and that one other stillbirth was shown to possess vaso-formative tissue in unusual quantity when examined by coronal section and would have met the criteria set for Group B cases in the horizontal section examination, thus underlining the patchy distribution of these proliferation changes (Fig. $4 a$ and $b$, overleaf).

If conclusions may be drawn from such a small number of cases, the suggestion is that vascular growth and particularly any unusual degree of proliferation is slowed down after birth.

The examination of the eyes injected with Indian ink added nothing to our knowledge of the times and weights at which vessels reached the ora, confirming only the variability already established. The flat preparations showed that in a one-week-old infant of $10 \mathrm{lb}$. birth weight, the foetal type of capillary net had practically disappeared. In a one-week-old full-term 


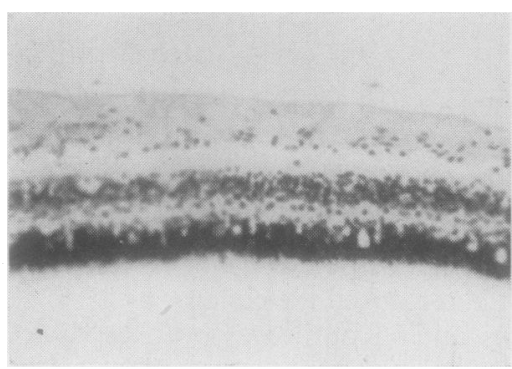

FIG. $4(a)$

FIG. 4 (a).-Case 52 (R) horizontal section showing normal quantities of vaso-formative tissue. $\times 120$.

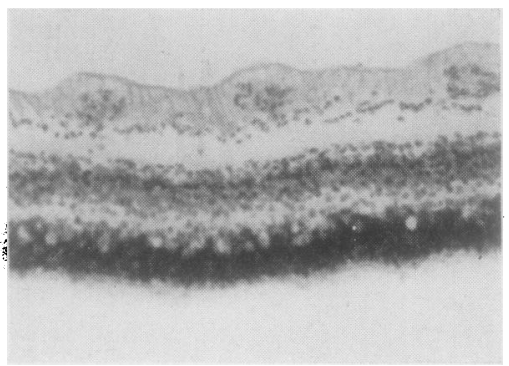

FIG. $4(b)$

(b).-Case 52 (R) coronal section through same area showing Group " B" type of vaso-formative tissue proliferation. $\times 120$.

infant of $6 \mathrm{lb}$. birth weight, it was patchily present at the periphery. At $5 \mathrm{lb} .5 \mathrm{oz}$. more was present, and at lower weights the net predominated peripherally. These preparations also showed the difference between the peripheral arterio-venous arcades of the completed vascular system and the open actively branching terminations of the developing system (Fig. 5). Some cases showed a double peripheral net, another explanation of the appearance of increased vascularity noted in the premature eye.

FIG. 5.-Injected retina of fullterm infant (birth weight $4 \frac{1}{2} \mathrm{lb}$.) to show open, actively-branching, embyonic type of capillary net at periphery and adult vascular pattern centrally. $\times 29$.

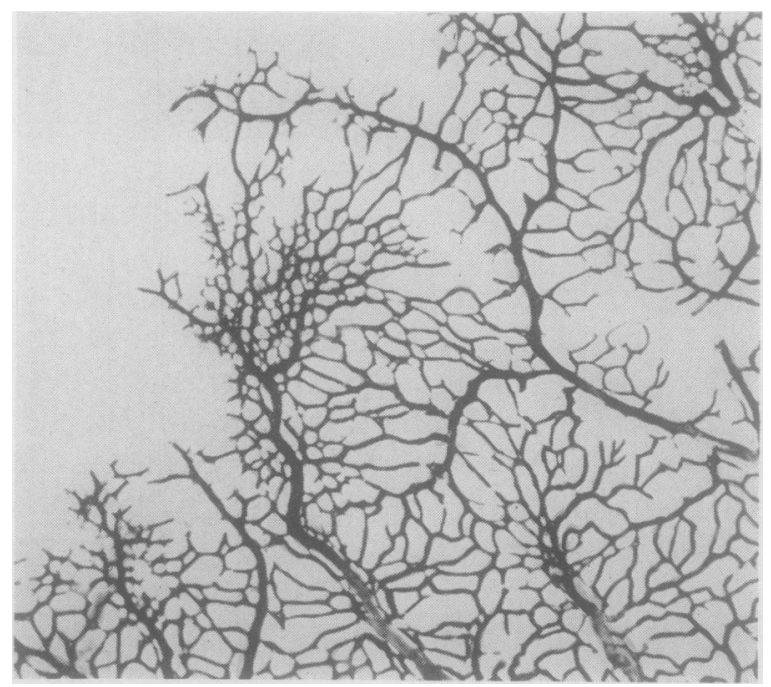

Michaelson's observations on developing and mature vascular systems were thus confirmed, and the possibility of visualizing the developing circulation in plan gave considerable aid in the interpretation of histological pictures seen on section. For instance, Fig. 6 shows the irregularity of vascular growth, with dense developing capillary systems near veins and relatively avascular areas near arteries. A section through this proliferating area, such as (1) and (2), could easily show the columns and minor masses of endothelial 
cells such as are seen at the advancing vascular edge. A section through (3), where the endothelial cells begin to branch out fanwise soon after leaving the vein, might give a whorl-like appearance.
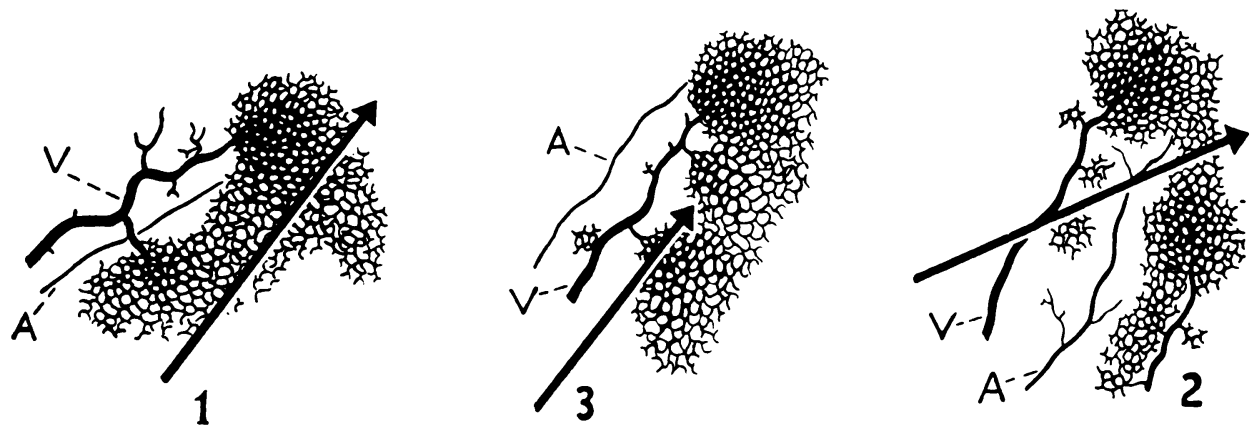

FIG. 6.-Irregularity of vascular growth with dense proliferating capillary systems near veins and relatively avascular areas round arteries. Section through 1 could show a column, and through 2 a minor mass of vaso-formative tissue, and through 3 a whorl-like appearance.

The more marked proliferations seen in the cases of Group $\mathrm{C}$ are less easily accepted as a normally developing vascular system, but might be regarded as an upper limit of normal variations in the course of development.

To determine whether the vascular changes described in Groups A, B, and $\mathrm{C}$ were within normal limits or had any pathological significance in relation to retrolental fibroplasia, the findings in these groups were analyzed and compared with the rest of the 100 premature births which showed no such changes. The results were as follows:

Weight Incidence

\begin{tabular}{c|c|c|c}
\hline Birth Weight (lb.) & No. of Cases & $\begin{array}{c}\text { Percentage } \\
\text { of Cases }\end{array}$ & $\begin{array}{c}\text { Incidence of this birth weight for comparison } \\
\text { in the analysis of 100 cases (per cent.) }\end{array}$ \\
\hline $4-5$ & 1 & 8 & 4 \\
$2-3$ & 9 & 69 & 55 \\
Under 2 & 3 & 23 & 24 \\
\hline
\end{tabular}

This analysis shows a preponderance in the under-3 lb. group, but, whilst a relationship with low birth weight is similar to the incidence of retrolental fibroplasia, this characteristic may be attributable to the dominance of this birth weight group in the total series, and is, therefore, of doubtful significance.

Eye Size.-No special relationship was established between the vascular changes and eye size. Five cases were below and eight cases were above the average equatorial diameter for their weight group.

Extra-uterine Age.-The age relationship of the cases in Groups A, B, and C follows the general trend of distribution in the 100 cases examined. It should be noted that one case was stillborn, one lived 25 minutes, and the oldest lived for 2 months. The duration of pregnancy varied from 29 to 37 weeks. 


\begin{tabular}{l|c|c|c}
\hline \multicolumn{1}{c|}{ Age } & No. of Cases & $\begin{array}{c}\text { Percentage } \\
\text { of Cases }\end{array}$ & $\begin{array}{c}\text { Incidence of age groups in the total series } \\
\text { of 100 cases for comparison (per cent.) }\end{array}$ \\
\hline Stillbirths & 1 & 8 & 13 \\
Less than 1 day & 3 & 24 & 26 \\
Less than 1 week & 7 & 52 & 47 \\
More than 1 week & 1 & 8 & 5 \\
Unknown & 1 & 8 & 5 \\
\hline
\end{tabular}

Vascular Maturity.-In only three cases had vessels actually reached the ora, and even in a 2-month-old baby patchy peripheral avascular areas were present. Compared with the average development figures, in five cases the retinal vessels had penetrated less far and in seven cases further towards the ora. This shows that the vascular changes described in the cases in Groups A, B, and C were associated with an incompleted retinal circulation and that the degree of incompleteness is variable and not directly related to the degree of angioblastic activity.

Retinal Folds.-These were present in twelve cases (92 per cent.). This might be indicative of the degree of post-mortem distortion, but in view of the incidence of folds in 90 per cent. of the total series of 100 cases, this result is unhelpful.

Retinal Congestion.-This was a prominent feature in ten cases (77 per cent.) compared with 20 per cent in the total series.

Retinal Haemorrhages.-These were present in five cases (39 per cent.), the incidence in the total series being also 39 per cent. The haemorrhages were of slight degree only, except in two cases, in which they were being invaded by endothelial cells.

Uveal Tract Congestion.-This was present in twelve cases (92 per cent.), an increase over the incidence in the total series of 57 per cent.

Inflammatory Infiltration.- This occurred in five cases (39 per cent.), comparable with the incidence in the total series of 40 per cent. In only one case was it at all extensive, when it was considered to be a form of extra-medullary haemopoiesis and then bore no apparent relationship to the retinal changes.

Cause of Death.-Anoxia usually played a part, but the stated causes were probably often unreliable, as post-mortem examinations were not always possible.

Associated Congenital Abnormality.-This was present in only one case of Fallot's tetralogy with absence of the right kidney and ureter and laryngeal stenosis.

Position of Vascular Changes.-This was most commonly from the equator forward to the anterior limit of vascularization, i.e. in the area of most active growth.

In considering these results it should be remembered that, for obvious reasons, the material included few full-term infants or babies who had lived for many weeks.

To sum up, the thirteen cases which fell in Groups A, B, and C showed an unusually marked degree of angioblastic activity, most commonly in front of the equator (in the area of most active vascular growth). These cases came predominantly from the 2 to $3 \mathrm{lb}$. birth weight group. Gestation times were 28 to 37 weeks and extra-u erine ages varied from stillbirth to 2 weeks. The affected retinae were usually not fully vascularized and only two cases showed haemorrhages of any size. The incidence of retinal and 
choroidal congestion was found to be greater than in the total series, but it will be seen that no causal association was, in fact, established, and that the incidence in the lower weight groups, a characteristic of debatable significance, and prematurity are the only doubtful links with retrolental fibroplasia.

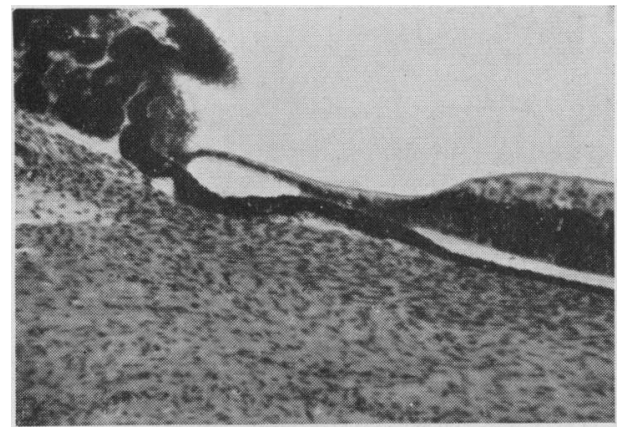

FIG. 7.-Separation of clear from pigmented cells of the pars plana of ciliary body. $\times 120$.

\section{Retinal Coaptation}

Attention was directed particularly towards any association of separation of the clear and pigmented cells of the pars plana (Fig. 7), or separation of the oral and adjacent retina from the underlying pigment epithelium, and of retinal and oral folds with any uveal or retinal characteristic which might be associated with retrolental fibroplasia. The results were as follows:

(1) Separation of the clear from the pigmented cells of the pars plana.-This occurred in varying degrees in eight cases:

\begin{tabular}{c|c|c|c|c|c|c}
\hline Birth Weight & Under 5 lb. & Under 4 lb. & Under 3 lb. & Under 2 lb. & Unknown & Total \\
\hline No. of Cases & 0 & 0 & 5 & 2 & 1 & 8 \\
\hline
\end{tabular}

(2) Separation of the clear and the pigmented cells from the basement membrane

(a) Moderate (34 cases):

\begin{tabular}{c|c|c|c|c|c|c}
\hline Birthweight & Under $5 \mathrm{lb}$. & Under $4 \mathrm{lb}$. & Under $3 \mathrm{lb}$. & Under $2 \mathrm{lb}$. & Unknown & Total \\
\hline No. of Cases & 1 & 3 & 22 & 7 & 1 & 34 \\
\hline
\end{tabular}

(b) Extensive (3 cases):

\begin{tabular}{c|c|c|c}
\hline Birthweight & under $3 \mathrm{lb}$. & Under $2 \mathrm{lb}$. & Total \\
\hline No. of Cases & 2 & 1 & 3 \\
\hline
\end{tabular}

The incidence of infiltration (42 per cent.) and of congestion (60 per cent.), of the uveal tract are comparable to an incidence in the total series of 100 cases of 40 and 57 per cent. respectively. The corresponding figures for separation of the clear cells of the pars plana only were 62 per cent. and 50 per cent.- -no significant difference for such a small number of cases.

(3) Oral Retinal Folds.-These were present in 95 per cent. The earliest sign of this oral folding was a separation of the oral retina and neighbouring clear cells of the pars plana from the subjacent pigment epithelium, which showed a notch directed forwards and inwards. Later the pigment epithelium separated from the basement membrane and became plicated, leading to a separation of the clear and pigmented cells for variable distance along the pars plana, reaching in some cases to the ciliary processes (Fig. $8 a, b, c$, and $d$ ). In one case, separation of the oral retina and clear cells of the pars plana was observed with no oral fold. 


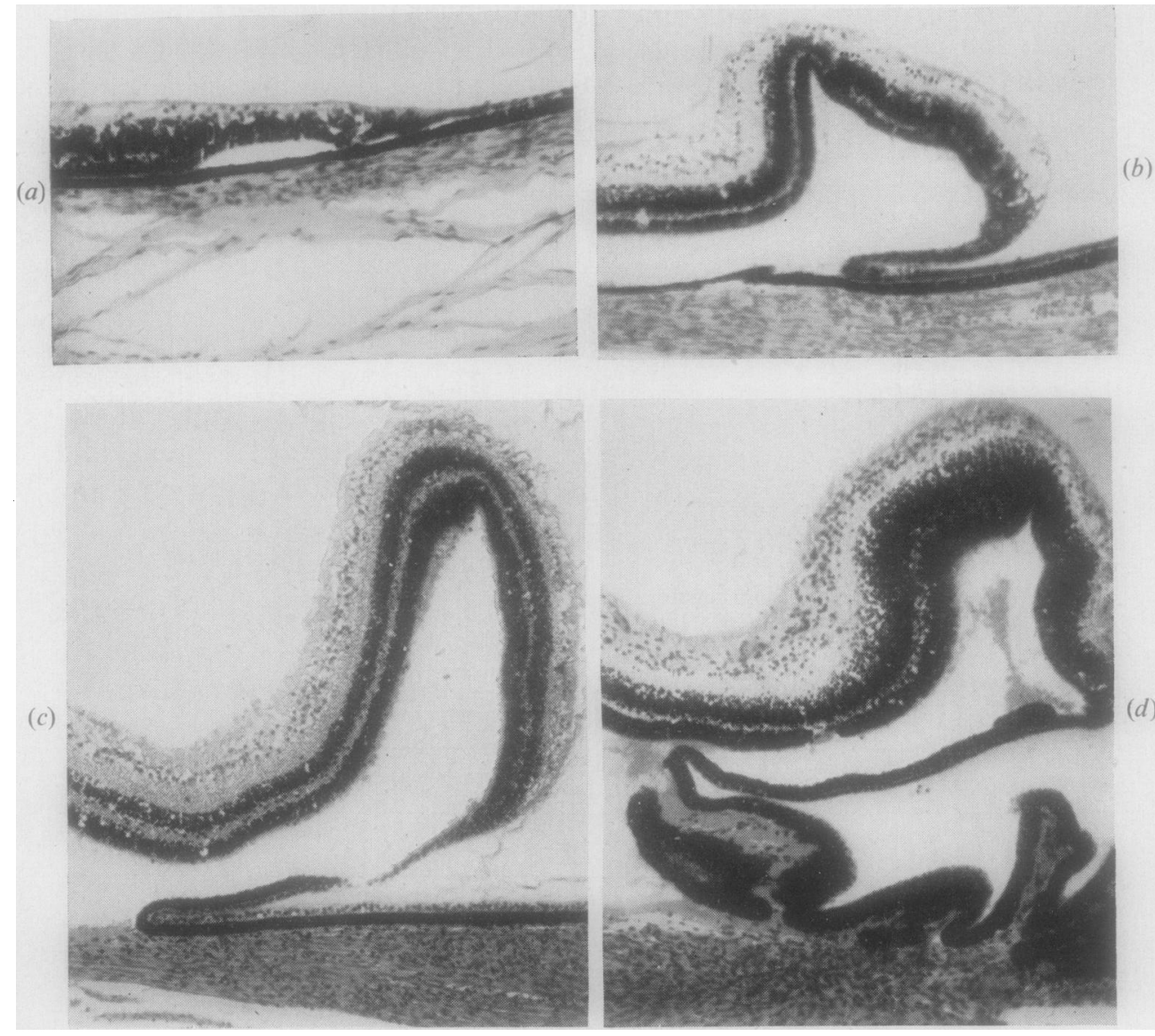

Fig. $8(a-d)$.-Four stages in formation of retinal oral fold. $\times 120$.

With a view to interpreting these results, consideration was given to the development of coaptation of the inner and outer layers of the optic vesicle.

At the 21-mm. stage of development (approx. 7 weeks' gestation), filaments from the external limiting membrane of the inner layer of the optic cup, representing the fore-runners of the rods and cones, come into contact with the pigmented epithelium of the outer wall. Coaptation of the inner and outer layers occurs at a later date, but clearly there can be no real cohesion between the layers until growth is complete. In the ciliary region the adhesion between the clear and pigmented epithelium is said to be firm (Mann, 1928). This ciliary region is formed by the growth of the margin of the optic cup past the equator of the lens, starting at the 48-mm. stage (approx. 10 weeks' gestation). At first, the layers of the cup are widely separated by the cavity of the primary optic vesicle (Fig. 9). At about the 65-mm. stage (approximately 12 weeks' gestation), adhesion is beginning between the inner and outer layers except just at the growing tip. The development of the ciliary region is a slow process: the folded growing edge extends, leaving the pars plana behind. At 5 months this structure is hardly visible; by 7 months the ora 


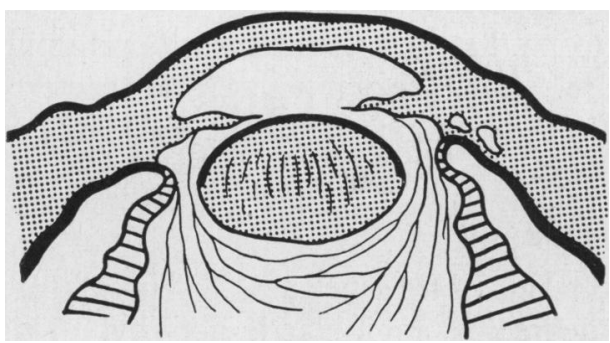

Fig. 9.-48-mm. stage embryo (about 11 weeks' gestation) showing separation of inner and outer layers of optic cup and growth of margin of cup past equator of lens. has reached the middle of the ciliary muscle, by 8 months the posterior third, and by 9 months (Fig. 10) the posterior border. (Bach and Seefelder, 1914; Mann, 1928).

To sum up these observations on retinal coaptation, developmental considerations preclude the anticipation of any firm adhesion between the layers of the optic cup in a premature eye. That cohesion is in fact poor is borne out by the fre-

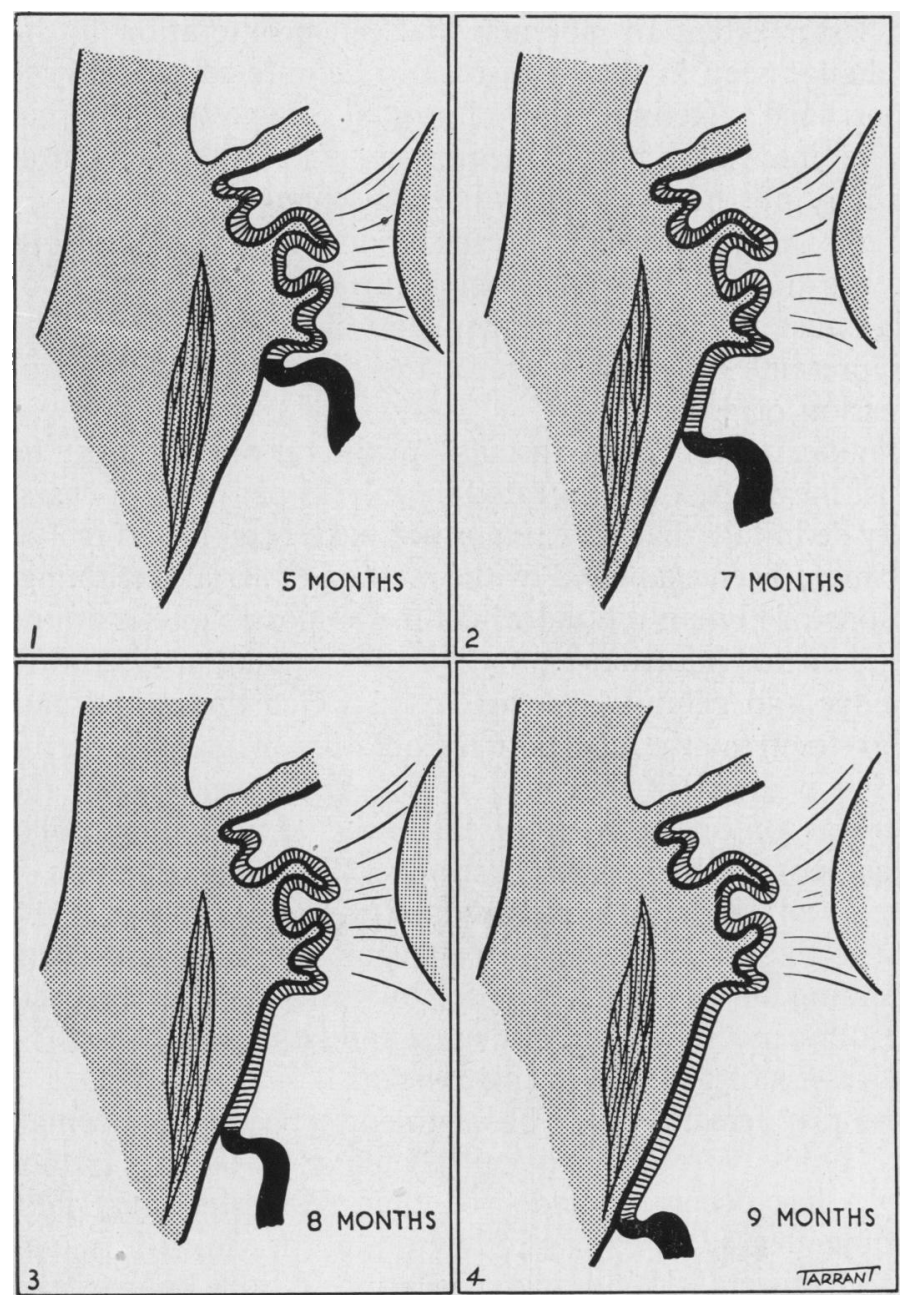

Fig. 10.-Development of pars plana of ciliary body and oral retina. quency of retinal folding $(90$ per cent.), separation of the clear cells of the pars plana $(8$ per cent.), and separation of the clear and the pigmented cells ( 37 per cent.), reported in this series. If these folds and separations are artefacts, which is probable, they demonstrate that little cohesion existed. The late development of the pars plana, first visible at the fifth month, makes it unreasonable to hold responsible any noxa acting before that date for detachment of the retina in this area, and, furthermore, no evidence of significant inflammation or other cause was found 
in this series. The significance of the true detachment of the clear cells of the pars plana would, therefore, seem to be that of a detachment developing in an immature eye, whatever the cause. Such detachments (due to many causes other than retrolental fibroplasia, i.e. trauma, infection, etc.) may in fact be seen in infant eyes.

\section{Discussion}

This investigation shows that in the retinae of 13 per cent. of premature babies there are signs of an unusual degree of angioblastic activity. This change is commonest in the lower birth weight groups and is associated with incomplete retinal vascularization. The literature on the pathology of retrolental fibroplasia has been reviewed by Ashton (1954), and there seems general agreement that thickening of the nerve fibre layer of the retina due to endothelial and to a lesser extent to mesenchymal cell proliferation is the earliest microscopic change seen in the disease. No definite relationship is established to haemorrhage. Retinal and choroidal congestion, retinal oedema, defects in the internal limiting membrane, and other structural abnormalities may or may not be due to post-mortem change.

Any consideration of the relationship of the endothelial proliferations discussed in this study to those described as occurring in the early stages of retrolental fibroplasia must of necessity remain entirely speculative. The histological picture represents only one stage in the continuous process of progression and regression of growth.

In assessing the significance of these vascular proliferations, it must be remembered that whilst they were demonstrated in only 13 per cent. of cases, it is not possible to say definitely that they might not have been found in 100 per cent. had the specimens been examined by the method of serial sectioning. The few flat preparations of human retinae which it was possible to examine after intravascular Indian ink injection showed very irregular proliferation both at the growing edge and behind. In the cat, in which the retinal vascular system is similar to man, the constant irregularity of growth of the developing blood vessels is a striking feature. This is also borne out by the fact that vertical sections of one human case showed typical glomerular whorls in an area judged normal by horizontal section (Fig. $4 a$ and $b$ ).

Amongst our material all gradations of vascular proliferation are to be seen, from the normal to the extreme, and their division into categories is an arbitrary process depending on the criteria adopted by the individual observer. Broadly speaking, the differences are ones of degree and situation, i.e. arising from more developed vessels or at the growing margin.

Whilst some of these proliferations may be destined to become abnormal, it is impossible to say, unless vitreous invasion has taken place, that pathological vascular growth has occurred, and even then regression may take place later. That some degree of over-production of primitive vascular tissue forms a common feature of developing circulations is well known, and may well be related to variations in oxygen tension within the foetal tissues. 
Keibel and Mall (1910-12), discussing normal vascular development, stated that a capillary net always exists at the periphery of the growing vascular tree. The main vessels arise by utilization of a single channel in the mesh and the co-incidental atrophy of the remainder.

These vascular endothelial changes have been considered to form the nucleus of retrolental fibroplasia (Reese and others, 1952), but, since they may so easily be explained by considerations of development and its anomalies, it is perhaps wiser to label them as an imponderable characteristic of the developing retina.

\section{Summary}

(1) The eyes from one hundred premature infants were examined with particular reference to the processes of retinal vascularization and coaptation.

(2) 13 per cent. of these cases showed an unusual degree of angioblastic activity, indicated by increased quantities of vaso-formative tissue in the nerve fibre layer. This change was associated with no characteristic of retrolental fibroplasia apart from low birth weight. There was no evidence to suggest that it was beyond the upper limits of normality.

(3) Separation of the clear from the pigmented cells of the pars plana, and of the clear and pigmented cells from the basement membrane, and the frequent, retinal folds were thought to be artefacts attributable to differential shrinkage of the coats of the eye, indicating only that adhesion between the layers of the optic cup is poorly developed in the premature eye.

(4) No evidence of a nucleus of retrolental fibroplasia was found, apàrt from the incomplete retinal vasculature, which is characteristic of prematurity.

I wish to thank Dr. Norman Ashton for his encouragement and advice. My thanks are also due to the medical illustration department of the Institute of Ophthalmology for photographs and diagrams. I am particularly grateful to Messrs. G. E. Knight, A. McNeil, and A. Johnson for technical assistance, and to Miss E. FitzGerald for secretarial help.

\section{REFERENCES}

Ashton, N. (1954). British Journal of Ophthalmology, 38, 385.

BACH, L., and SEEFELDER, R. (1914). "Atlas zur Entwicklungs-geschichte des menschlichen Auges ". Engelmann, Leipzig and Berlin.

Dixon, J. M., and Paul, E. V. (1951). Amer. J. Ophthal., 34, No. 5, (May) Pt. 2, p. 182.

Priedenwald, J. S., Owens, W. C., and OWens, E. U. (1952). Trans. Amer. ophthal. Soc., 49, 207:

Heath, P. (1950). Arch. Ophthal. (Chicago), 44, 245.

(1951). Amer. J. Ophthal., 34, 1249 .

Keibel, F., and MALl, F. P. (1910-12). "Manual of Human Embryology". Lippincott, Philadelphia and London.

ManN, I. (1928). "The Development of the Human Eye". University Press, Cambridge.

MICHAELSON, I. C. (1948). Trans. ophthal. Soc. U.K., 68, 137.

ReESE, A. B., and BlODi, F. C. (1951). Amer. J. Ophthal., 34, 1.

- and Locke, J. C. (1952). Ibid., 35, 1407.

SERPELL, G. (1954). British Journal of Ophthalmology, 38,

TERRY, T. L. (1942). Amer. J. Ophthal., 25, 203.

Versari, R. (1910). Anat. Anz., 35, 105.

WolfF, E. (1950). Proc. roy. Soc. Med., 43, 227. 